\title{
Gestão da qualidade e avaliação dos serviços de hematologia e hemoterapia na perspectiva no Programa Nacional de Qualificação da Hemorrede
}

\author{
Jane Terezinha Martins \\ Glauciene Analha Leister \\ Cláudio Medeiros Santos
}

\section{SciELO Books / SciELO Livros / SciELO Libros}

MARTINS, J.T., LEISTER, G.A., and SANTOS, C.M. Gestão da qualidade e avaliação dos serviços de hematologia e hemoterapia na perspectiva no Programa Nacional de Qualificação da Hemorrede. In: SOUZA, M.K.B., comp. Planejamento e gestão em saúde: caminhos para o fortalecimento das hemorredes [online]. Salvador: EDUFBA, 2018, pp. 73-88. ISBN 978-85-232-2027-3.

https://doi.org/10.7476/9788523220273.0005.

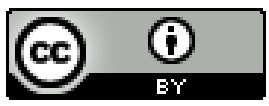

All the contents of this work, except where otherwise noted, is licensed under a Creative Commons Attribution 4.0 International license.

Todo o conteúdo deste trabalho, exceto quando houver ressalva, é publicado sob a licença Creative Commons Atribição $\underline{4.0}$. 


\title{
Gestão da qualidade e avaliação dos serviços de hematologia e hemoterapia na perspectiva no Programa Nacional de Qualificação da Hemorrede
}

\author{
Jane Terezinha Martins \\ Glauciene Analha Leister \\ Cláudio Medeiros Santos
}

\section{Introdução}

O papel fundamental da gestão é levar as organizações ou serviços a cumprir a sua missão. Na expressão de Magretta e Stone (2002) "criação de valor" é o elemento fundamental, a missão da gestão. Valor, no sentido apresentado pelas autoras, significa capacidade de atender às reais necessidades daqueles que são os destinatários, os usuários, os consumidores dos serviços e produtos oferecidos pela organização. Quer seja valor econômico, aplicado no contexto das organizações privadas, quer seja valor social ou bem-estar social, aplicado para as organizações públicas, sem fins lucrativos.

Com posicionamento semelhante, Mintzberg (2010, p. 61) destaca que a suprema finalidade da gestão é "garantir que a unidade sirva ao seu propósito básico”, realizando para isso, ações eficazes. 
Em suas conclusões sobre a natureza da gestão Mintzberg (2010, p. 23) propõe que gestão não é ciência, muito menos profissão. Gestão é uma prática, aprendida principalmente com a experiência e enraizada no contexto.

Para o autor, a gestão eficaz, compreendida como uma prática, está associada a aplicação de três elementos essenciais: a arte, vista como discernimento criativo, visão, intuição, ideias; a habilidade prática, que guarda estreita relação com a experiência, com a capacidade de fazer conexões, de compreender e resolver problemas; e finalmente, a ciência, entendida como a aplicação de métodos, uso sistemático da análise. Como estes elementos interagem sempre nos limites de um dado contexto, pode-se afirmar que não existe a melhor maneira de fazer gestão. (MINTZBERG, 2010)

Na gestão de serviços públicos de saúde, em particular, na gestão dos serviços públicos de hematologia e hemoterapia os desafios se ampliam. São serviços localizados em diferentes regiões, contextos e culturas, com estrutura jurídica e organizacional variada; uns ligados a Administração Direta Estadual, outros ligados as universidades e outros mais estruturados nos modelos ${ }^{1}$ de autarquias, fundações e organizações sociais. Os seus gestores, nestes variados contextos, empregando suas habilidades, suas ciências e suas artes, lançam mão de instrumentos, métodos, práticas e modelos, buscando, ao fim e ao cabo, fazer com que estas organizações cumpram a sua missão de disponibilizar sangue e componentes na quantidade compatível com as necessidades e demandas e com a qualidade adequada para maior segurança e efetividade dos procedimentos de atenção à saúde, particularmente os transfusionais.

Em busca destas ações eficazes de gestão, uma das tecnologias gerenciais empregadas frequentemente nos serviços de hematologia e hemoterapia é a gestão da qualidade. Nestes serviços, a qualidade do produto final é consequência de uma complexa rede de atividades e processos, que vão desde a adequada seleção do doador até a disponibilização e transporte do produto para os Centros de Atenção a Saúde, onde serão utilizados. Não obstante os avanços das práticas de produção e modernização da gestão dos serviços, esta qualidade pode ver-se comprometida em algumas das etapas da cadeia,

1 Veja definições e características de cada modelo organizativo em Conselho Nacional de Secretários de Saúde (1995). 
podendo, por conseguinte, ampliar o potencial de riscos e danos à saúde do cliente final. Devido a isso os serviços hemoterápicos devem incorporar em suas atividades conceitos de qualidade e boas práticas de produção. (LEDESMA RODRÍGUEZ; FRANCO CAMA, 2007)

Para Berwik (1991), citado por Malik e Schiesari (1998, p. 27), a gestão da qualidade nos serviços de saúde está fundamentada em alguns princípios, dentre eles o de que "[...] o trabalho produtivo é realizado através de processos [e] [...] a principal fonte de falhas de qualidade são os problemas nos processos", devendo, por isso, o controle de qualidade ter que se concentrar nestes conjuntos de atividades. Na sua lista de princípios, Berwik (1991 apud MALIK; SCHIESARI, 1998, p. 27) assevera que a “[...] administração da qualidade emprega três atividades básicas, estreitamente inter-relacionadas: planejamento da qualidade, controle da qualidade e melhoria da qualidade".

Para Donabedian (1990), a qualidade da atenção à saúde é definida como o "grau em que os meios mais desejáveis" são empregados para a melhoria na saúde. Sangue e componentes seguros e com padrões adequados de qualidade podem se entendidos como um "meio desejável" apresentado no conceito desse autor. Destaca ele que nenhuma avaliação da qualidade seria possível sem a existência e a combinação de critérios e padrões. Os critérios seriam os elementos da estrutura, processo e resultados e os padrões declarações quantitativas mais específicas que permitam avaliar frequência e magnitude.

Antes que qualquer um destes três elementos (estrutura, processo e resultados) seja utilizado para avaliação da qualidade, é necessário que as relações (causa e efeito) entre eles sejam conhecidas e estabelecidas, o que implica tanto conhecimentos das ciências organizacionais como também das ciências clínicas ou médicas. (DONABEDIAN, 1988)

Aplicando a tríade apresentada por Donabedian (1990) no âmbito dos Serviços de Hemoterapia, tem-se na "estrutura" todos os recursos materiais, humanos, de infraestrutura e tecnologias empregadas na produção de hemocomponentes, incluindo, na parte de recursos humanos, tanto as características quantitativas como as relacionadas a competência e formação profissional. Na dimensão dos "processos", encontra-se o modo como as atividades são executadas, encadeadas e organizadas de forma a gerar os produtos. Por 
fim, os produtos gerados (sangue e componentes) compõem a dimensão dos "resultados", incluindo também aqui os efeitos ou a modificação dos estados de saúde gerados após a prática transfusional.

$\mathrm{Na}$ atualidade, a gestão da qualidade nos serviços de hemoterapia foi incorporada a legislação sanitária sendo sua aplicação, não mais uma escolha do gestor, mas uma exigência legal. A Portaria GM n ${ }^{\circ} 158$ do Ministério da Saúde, de 4 de fevereiro de 2016, que redefine o regulamento técnico de procedimentos hemoterápicos, estabelece no capítulo II - Da Garantia da Qualidade, os princípios gerais do sistema da qualidade que deve ser mantido pelo serviço. Neste capítulo II, o artigo 240 estabelece:

Art. 240. O serviço de hemoterapia disporá de políticas e ações que assegurem a qualidade dos produtos e serviços garantindo que os procedimentos e processos ocorram sob condições controladas. § $1^{\circ}$ São, entre outras, as ações de que trata o 'caput': I - métodos e ferramentas de melhoria contínua; II - processos de proposição de ações preventivas e corretivas; e III - tratamento das reclamações e sugestões dos usuários. § $2^{\circ} \mathrm{O}$ desempenho dos processos será acompanhado por meio de indicadores e definição de metas. (BRASIL, 2016a)

A gestão de serviços e, em particular a gestão da qualidade, guarda uma relação muito próxima com a prática da Avaliação. Vieira-da-Silva (2014) chega a afirmar que a avaliação é um dos componentes do processo de gestão e pode ser realizada objetivando, por exemplo, determinar se um dado programa (ou mesmo um dado serviço) está produzindo os resultados que deveria. A avaliação contribui para a melhoria do processo decisório e deve ser vista pela gestão como um instrumento para o enfrentamento e a resolução de problemas nos serviços ou programas de saúde. (TANAKA; MELO, 2008)

Nesta mesma linha de pensamento Malik e Shiesari $(1998$, p. 9) afirmam que:

A avaliação tenta trazer respostas a perguntas a respeito dos resultados esperados de um programa, ação ou serviço. O objeto pode ser o impacto ou até os processos. Ambos os focos guardam estreitas semelhanças com o desenvolvimento do pensamento 
da qualidade, cujo marco inicial deu-se via inspeções do produto final, até chegar à avaliação da qualidade dos processos (ou sua administração) antes que o produto final saia da fábrica. O fundamental, quando se fala em avaliação, é ter claro que ela serve para definir se algo é ou não bom, digno de ser prosseguido ou deve ser interrompido. Para isso, devem-se explicitar os critérios utilizados, a que necessidades ou interesses esses critérios respondem e quem pode ser favorecido ou prejudicado em presença desses resultados.

O Serviço de Hematologia e Hemoterapia está oferecendo Sangue e Componentes segundo os padrões de qualidade estabelecidos pelas normas sanitárias, pelas boas práticas de produção ou pelos padrões de qualidade desejados? A gestão está atuando adequadamente? Os processos produtivos estão ajustados? Onde estão os problemas? O que pode ser melhorado? O que está ótimo? São todas perguntas de gestão que a prática sistemática da avaliação pode responder.

Nesse contexto, o Programa Nacional de Qualificação da Hemorrede (PNQH) é considerado importante ferramenta para a identificação de cenários nos Serviços de Hematologia e Hemoterapia (SHH) e, consequentemente, potente estratégia para apontar oportunidades de melhorias técnicas e gerenciais na Hemorrede e para promover o aperfeiçoamento dos processos de trabalho na premissa da gestão da qualidade. Assim, com o intuito de possibilitar diagnóstico situacional da Hemorrede e orientar o desenvolvimento de ações visando ao aumento da segurança transfusional para todos os serviços do país, em 2008, o PNQH foi criado com os seguintes objetivos (BRASIL, 2016b):

- Promover a qualificação técnica e gerencial da Hemorrede Pública Nacional;

- Identificar áreas críticas/estratégicas para priorizar investimento de recursos na Hemorrede;

- Implantar e implementar o processo de melhoria contínua nos SHH, por meio da avaliação permanente dos processos de trabalho; 
- Apoiar a elaboração e monitorar a evolução de Planos de Ação (PA) dos SHH, para as não conformidades e/ou recomendações apontadas no relatório de visita;

- Promover a cooperação e a integração entre SHH públicos do país;

- Prestar consultorias técnicas e realizar capacitações conforme necessidades apontadas nas visitas;

- Motivar mudanças internas nos SHH, como a implantação e/ou implementação do sistema de gestão da qualidade, a certificação e/ ou acreditação da unidade, capacitação dos profissionais, enfim a busca pela excelência da qualidade dos serviços e produtos hemoterápicos e hematológicos.

Em 2015, um estudo de avaliabilidade do PNQH, aplicado no Hemocentro do Ceará (SOBREIRA, 2015), desenvolveu o Modelo Lógico do Programa, analisando os modelos: causal, operacional e lógico teórico. No modelo causal, identificou o problema que o programa pretende resolver ou minimizar. Já no modelo lógico operacional identificou a estrutura, os processos, e o objetivos de produção, finalizando no modelo lógico teórico, a identificação dos objetivos e finalidades da intervenção. O estudo concluiu que o programa contribui para impulsionar mudanças e melhorias nos SHH (Figura 1).

Considerando a complexidade dos objetivos definidos, para o alcance dos mesmos e para a operacionalização do programa foi sistematizada ampla gama de ações, inclusive com o consenso da Comissão de Assessoramento Técnico (CAT) do PNQH e de gestores da Hemorrede. Assim, considerando como referência, os padrões de boas práticas de produção e das normas vigentes, estabeleceu-se que seriam realizadas visitas de avaliação formativas e processuais, com o intuito de promover o aperfeiçoamento dos processos de trabalho nos Serviços de Hematologia e Hemoterapia, buscando se distanciar da tônica de auditoria.

"Avaliar para conhecer, conhecer para ajudar, ajudar para melhorar" foi o lema adotado, traduzindo, portanto, a essência do programa, de além de promover o levantamento de informações para a gestão dos SHH, desenvolver uma rede de relacionamentos técnicos e gerenciais capaz de induzir mudan- 


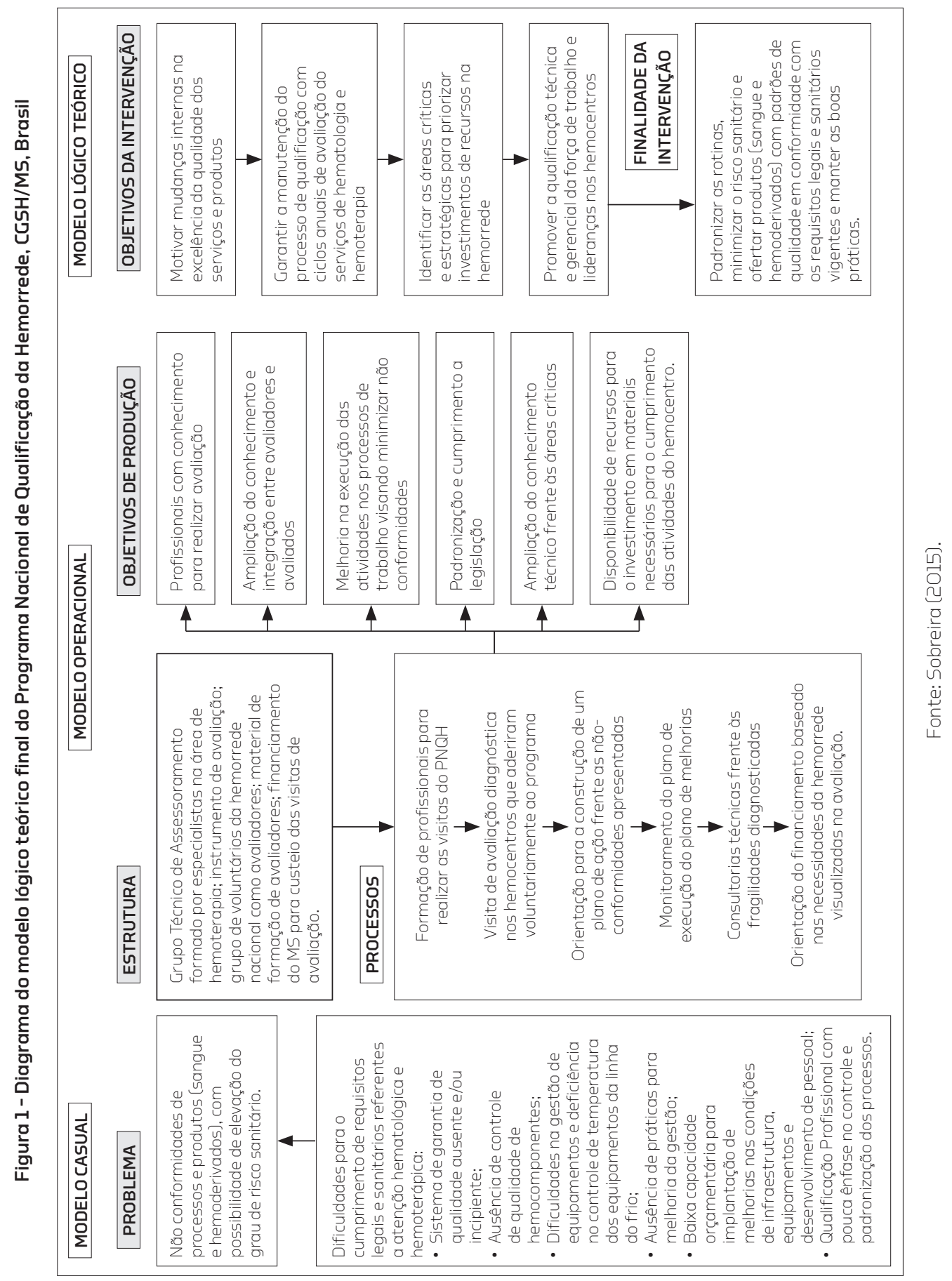


ças locais de melhoria na qualidade dos produtos e serviços hematológicos e hemoterápicos.

Com a concepção citada acima, acordou-se a conformação das avaliações em ciclos de visita e revisita, em que no primeiro momento seria realizado o diagnóstico situacional do SHH visitado e na revisita seriam analisadas as implementações das ações de melhorias apontadas na visita. Dessa forma, esse ciclo estaria contemplado nas seguintes etapas: planejamento da visita de avaliação do SHH, avaliação nos SHH pela equipe de avaliadores, planejamento das ações de melhoria, execução das ações de melhoria pelos SHH visitados, reavaliação dos resultados alcançados pelas ações de melhoria (revisita) e renovação dos planos de ações, conforme ilustrado na Figura 2.

Figura 2 - Ciclo de melhorias do Programa Nacional de Qualificação da Hemorrede

\section{COMPREENDENDO O CICLO DO PNQH}

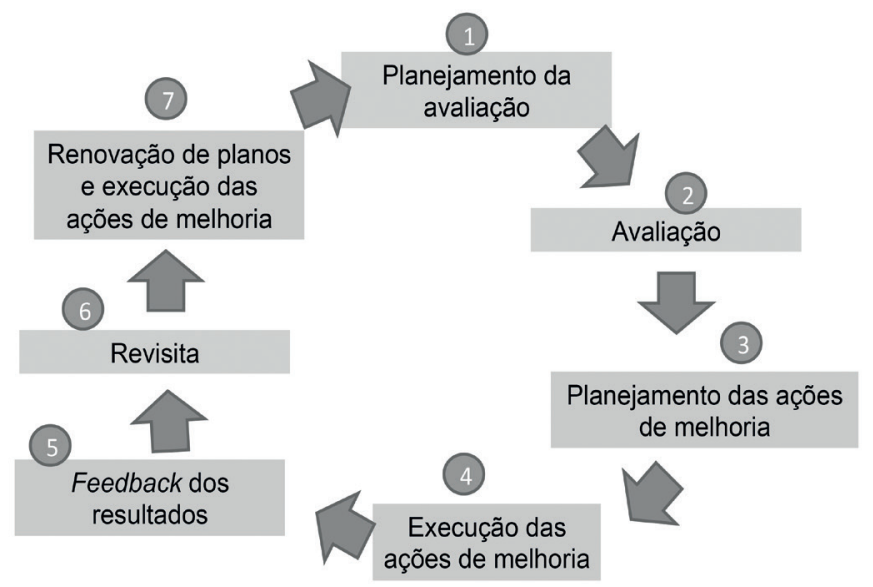

Fonte: adaptada de Brasil (2016).

Além da definição do ciclo apontado acima, identificou-se a necessidade da utilização de um instrumento para nortear os avaliadores durante as visitas, para padronizar as informações obtidas, para propiciar avaliação 
de todos os setores do SHH e para possibilitar análise técnica e gerencial de cada setor. Para elaboração do referido roteiro, realizou-se força tarefa com a participação de treze profissionais, contando com especialistas dos SHH e da CGSH e com a representação de diferentes formações profissionais: médicos, enfermeiros, farmacêuticos bioquímicos e biomédicos. Para o desenvolvimento do roteiro foram utilizados os instrumentos (checklist) da Fundação Centro de Hematologia e Hemoterapia de Minas Gerais, do Centro de Hemoterapia e Hematologia do Rio de Janeiro, do Centro de Hematologia e Hemoterapia de Santa Catarina e do Centro de Hematologia e Hemoterapia Hemocentro de Campinas/Universidade Estadual de Campinas (Unicamp), buscando contemplar todas as atividades técnicas, administrativas e gerenciais de um SHH, abrangendo tanto a Atenção Hemoterápica, quanto a Hematológica, com ênfase em coagulopatias e, posteriormente, em hemoglobinopatias.

A primeira versão do roteiro utilizado nas visitas de avaliação era composta por 23 planilhas e 540 requisitos. Ao longo do tempo e com a experiência desenvolvida pela utilização do roteiro do programa, atualmente o instrumento de avaliação contém 27 planilhas, com 336 requisitos.

Para análise dos requisitos contidos no instrumento, foram definidos os seguintes parâmetros de pontuação: totalmente conforme (C), parcialmente conforme (PC), não conforme (NC) e não se aplica (NA). O instrumento também contemplou campos para o registro de observações e recomendações, como é possível visualizar na Figura 2. Cabe ressaltar que no PNQH foi instituído o parâmetro de pontuação PC (parcialmente conforme), característica diferencial dos demais instrumentos de avaliação utilizados por outras instituições e que embute significados de estímulos aos SHH, pois promove que os serviços que possuem alguma evidência e/ou prática parcial de atendimento do requisito busquem seu cumprimento total.

A seguir, a Figura 3 ilustra como estão organizados os requisitos e os parâmetros de pontuação utilizados no instrumento de avaliação. 
Figura 3 - Requisitos e parâmetros de pontuação utilizados no instrumento de avaliação do PNQH

\begin{tabular}{|c|c|c|c|c|c|c|}
\hline \multicolumn{7}{|c|}{ Nome da instituição: } \\
\hline \multicolumn{7}{|c|}{ Responsável pela área: } \\
\hline \multicolumn{7}{|c|}{ Data da avaliação: } \\
\hline $\mathrm{N}^{\circ}$ & Requisitos & $\mathrm{C}$ & $\mathrm{PC}$ & NC & NA & Observações \\
\hline 1 & 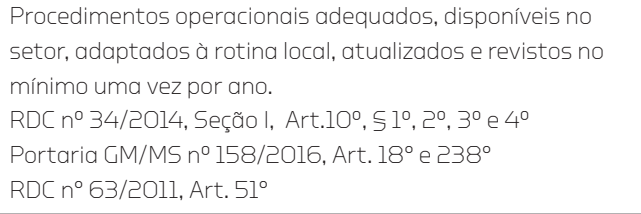 & & & & & \\
\hline ट & 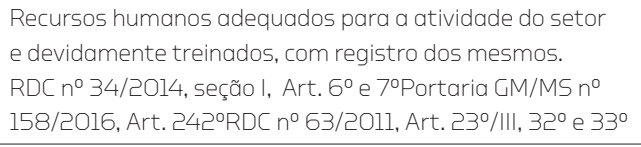 & & & & & \\
\hline 3 & $\begin{array}{l}\text { Área e condições de trabalho adequadas. } \\
\text { RDC n 34/2014, seção I, Art. } 8^{\circ} \\
\text { RDC n 50/ट00ट } \\
\text { Portaria GM/MS n 158/2016, Art. } 255^{\circ}\end{array}$ & & & & & \\
\hline 4 & $\begin{array}{l}\text { Técnica, reagentes e controles utilizados adequados } \\
\text { (citar a técnica utilizada).RDC n 34/2014, Seção VI, Art. } \\
\text { 7200 Portaria GM/MS n 158/2016, anexo VII }\end{array}$ & & & & & \\
\hline 5 & 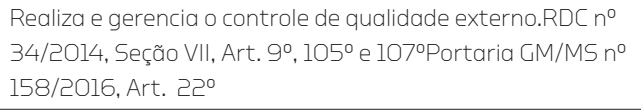 & & & & & \\
\hline 6 & $\begin{array}{l}\text { Realiza controle de qualidade interno, incluindo validação } \\
\text { dos procedimentos.RDC nº 34/2014, Seção VII. Art. 9. } \\
105^{\circ} \text { e } 107^{\circ} \text { Portaria GM/MS n 158/2016, Art. } 22^{\circ}\end{array}$ & & & & & \\
\hline \multicolumn{2}{|c|}{ Total } & O & 0 & 0 & 0 & \\
\hline
\end{tabular}

Fonte: adaptada de Brasil (2016).

Cabe salientar que a avaliação da variação do percentual de conformidade dos SHH deve ser realizada criticamente, a partir de análise interna do instrumento de avaliação e dos relatórios de qualificação do $\mathrm{PNQH}$, atentando-se para a obtenção dos seguintes resultados:

- Avaliação geral dos SHH por região;

- Avaliação dos SHH por setores;

- Comparativo da evolução de conformidade geral por serviço, por região e entre ciclos das visitas e revisitas técnicas. 
Para a compilação dos resultados, a análise de conformidade dos requisitos avaliados é realizada em cada planilha do roteiro de avaliação, sendo calculado ao final da avaliação o percentual de conformidade, de parcial conformidade e de não conformidade, item por item, de cada área/planilha. A partir desse cálculo setorial, realiza-se o consolidado geral do serviço, que expressa o cenário da avaliação de conformidade, como é possível observar na Figura 4, que permite a visualização gráfica dos percentuais de conformidade, parcial conformidade e não conformidade por setor.

Figura 4 - Distribuição percentual dos critérios de conformidade do $\mathrm{SHH}$, por setor e por ano da visita

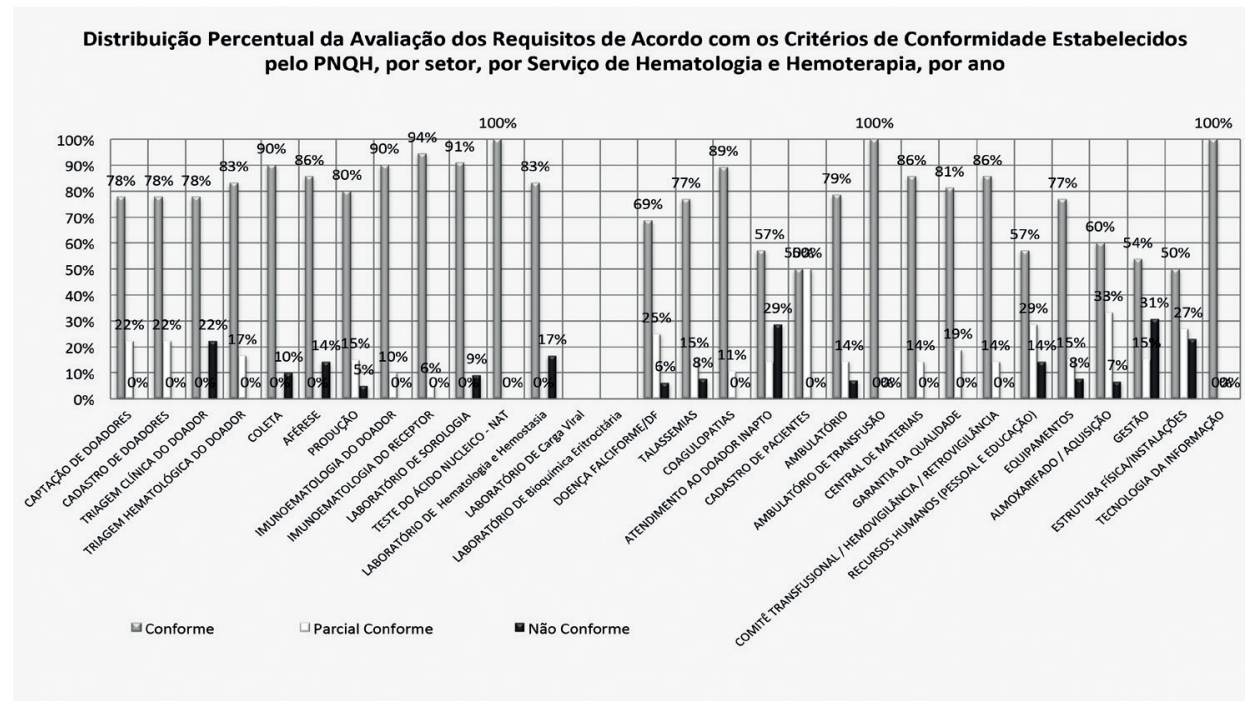

Fonte: adaptada de Brasil (2016).

Outras conformações gráficas são possíveis de se obter com os dados levantados após compilação das informações das visitas de avaliação, dentre as quais é possível visualizar a distribuição percentual dos critérios de conformidade por região do país (Figura 5), o que permite a análise e o direcionamento de ações e de investimentos a serviços com maior necessidade de melhorias. 
Figura 5 - Distribuição percentual gráfica dos critérios de conformidade por região entre 2008 a 2015

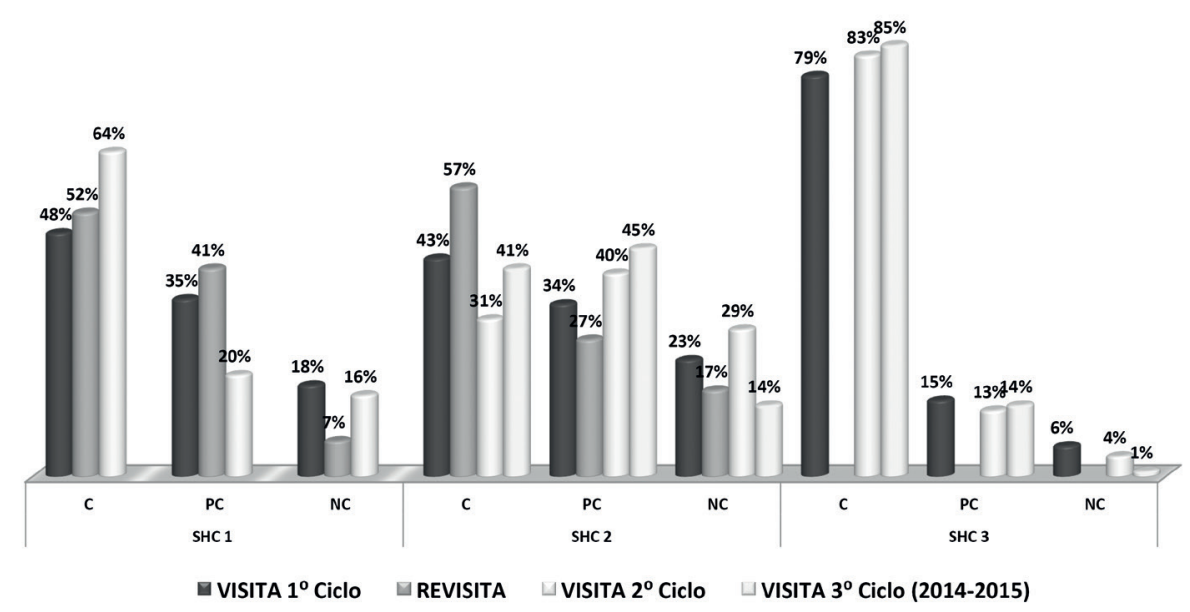

Fonte: adaptada de Brasil (2016).

A partir dos dados consolidados e analisados, com base nas não conformidades encontradas nas visitas, o PNQH orienta a elaboração do plano de ação (PA) para que o SHH visitado implemente estratégias para a correção da não conformidade ou implantação de melhorias. O compartilhamento de experiências, de boas práticas e de recomendações não ocorre apenas na consolidação final das informações, pois é possível cooperação técnica aos SHH durante as visitas. Além disso, o apoio aos SHH também ocorre por meio de consultorias, que podem ser direcionadas para eventuais dificuldades que surgirem durante a elaboração e/ou execução do PA ou destinadas a alguma fragilidade específica de algum setor ou processo de trabalho, conforme necessidade do serviço.

Dessa forma, conclui-se que os principais produtos esperados das visitas de avaliação do PNQH são o diagnóstico situacional da Hemorrede e a consolidação dos dados e evidências por meio dos relatórios gerados a partir das visitas. A análise e a interpretação adequada das informações levantadas é etapa fundamental para subsidiar as ações de melhoria e o aperfeiçoamento da qualidade dos produtos e serviços ofertados aos usuários do SUS.

Apesar da qualidade do roteiro oferecer subsídios para avaliação técnica e gerencial adequada, entendeu-se como fundamental importância para o de- 
senvolvimento da visita a formação de avaliadores, o que levou a identificação de 27 profissionais que atendessem o perfil desejado e que participassem, em seus serviços, de auditorias internas e/ou supervisão técnica, a fim de compor a equipe de avaliadores do programa. Com o intuito de instrumentalizar, padronizar a postura desses colaboradores para a compreensão dos objetivos do programa foram elaboradas Diretrizes para a conduta dos avaliadores do PNQH, compostas por itens que expressassem os objetivos do programa e que orientassem os profissionais quanto as suas atuações durante as visitas.

Com a experiência do primeiro ciclo de visitas, identificou-se a necessidade de formação de maior número de avaliadores para tornar mais efetiva a implementação do Programa, o que levou o PNQH a formar, ao longo do tempo, 375 colaboradores que atuam de forma voluntária, estabelecendo redes de parceria na Hemorrede e perseguindo o objetivo coletivo de promover o aperfeiçoamento da Atenção Hematológica e Hemoterápica aos usuários do SUS.

Com a sistemática de atuação contextualizada acima, o Programa se destina à Hemorrede dos 26 estados e do Distrito Federal, rede esta composta, em cada estado, pelos seguintes serviços: Hemocentros Coordenadores (HC), Hemocentros Regionais (HR), Hemonúcleos (HN), Unidades de Coleta e Transfusão (UCT), Unidades de Coleta (UC), Agências Transfusionais (AT) e da Assistência Hemoterápica (AH). Cabendo ressaltar a peculiaridade do estado de São Paulo, que devido ao grande quantitativo de bolsas coletadas e transfundidas no estado, possui seis hemocentros regionais com característica de serviço coordenador, que em seus âmbitos de atuação, também apoiam as ações do PNQH.

O PNQH priorizou suas ações para os HC, porém, considerando a estrutura da hemorrede nacional, que atualmente conta com aproximadamente 2029 SHH, sendo, dentre eles, mais de 50\% AT (AGÊNCIA NACIONAL DE VIGILÂNCIA SANITÁRIA, 2015); a complexidade que envolve a segurança transfusional; e reconhecendo que cada parte isolada do processo pode influenciar na qualidade do produto final ofertado, entendeu-se que se tornava imprescindível a inserção do Sistema de Gestão da Qualidade também nas AT, previsto em regulamentação, contemplando, portanto, a descrição dos procedimentos, a realização de registros, o tratamento de não conformidades (NC), a inspeção de reagentes e de materiais, o gerenciamento e o monitoramento de indicadores e, principalmente, o adequado armazenamento, manuseio e apli- 
cação dos hemocomponentes. Assim, em 2011 foi criado o Programa Estadual de Qualificação da Hemorrede (PEQH), o que exigiu adaptações no instrumento de avaliação para atender as características principalmente das AT e ampliação da formação de avaliadores regionais. Cabe ressaltar que o PEQH fomenta que o HC gerencie sua hemorrede estadual/regional e, portanto, a operacionalização deste programa (PEQH) é de responsabilidade do HC.

A operacionalização e logística do PNQH e do PEQH são semelhantes, divergindo conforme as características locais da área de abrangência do PEQH. Pela conformação das ações do PNQH e PEQH ao longo dos anos, conclui-se que os programas se constituem como importante ferramenta de gestão, pois permite que os SHH tenham conhecimento de sua Hemorrede, conheçam suas fragilidades e sistematicamente elaborem melhorias para as não conformidades identificadas.

Por fim, ao reconhecer a potencialidade do $\mathrm{PNQH} / \mathrm{PEQH}$, almeja-se que a experiência descrita acima possa incentivar os leitores a buscarem ferramentas de gestão que provoquem transformações em suas práticas de saúde, pois na hematologia e hemoterapia essas estratégias têm sido importante gatilho para superação de entraves da gestão, pois promove a cooperação técnica entre os SHH públicos do país; não possui caráter fiscalizatório e, sim, de apoio aos serviços; e motiva mudanças internas nos processos de trabalho, visando à excelência da qualidade dos produtos e serviços hematológicos e hemoterápicos.

\section{Referências}

AGÊNCIA NACIONAL DE VIGILÂNCIA SANITÁRIA (Brasil). Serviços de hemoterapia cadastrados no Sistema Nacional de Cadastro de Serviço de Hemoterapia - HEMOCAD. Brasília, DF, 2015. Disponível em: <http://wwwl. anvisa.gov.br/anvisa/hemocad/RelatoriosHemocad.jsp >. Acesso em: 13 maio 2016.

BRASIL. Ministério da Saúde. Portaria n ${ }^{\circ}$ 158, de 4 de fevereiro de 2016. Redefine o regulamento técnico de procedimentos hemoterápicos. Diário Oficial da República Federativa do Brasil, Brasília, DF, 5 fev. 2016a. Seção 1, p. 37. Disponível em: <http://pesquisa.in.gov.br/imprensa/jsp/visualiza/index. jsp?jornal=1\&pagina=37\&data=05/02/2016>. Acesso em: 5 mar. 2016. 
BRASIL. Ministério da Saúde. Portaria n ${ }^{\circ}$ 2.712, de 12 de novembro de 2013. Redefine o regulamento técnico de procedimentos hemoterápicos. Diário Oficial [da] República Federativa do Brasil, Brasília, DF, 13 nov. 2013. Seção 1, p. 106. Disponível em: <http://bvsms.saude.gov.br/bvs/saudelegis/gm/2013/ prt2712_12_11_2013.html>. Acesso em: 10 jan. 2016.

BRASIL. Ministério da Saúde. Secretaria de Atenção à Saúde. Departamento de Atenção Especializada e Temática. Guia para implementar avaliações nos serviços de hematologia e hemoterapia na perspectiva do Programa Nacional de Qualificação da Hemorrede. Brasília, DF, 2016b. Disponível em: <http://bvsms. saude.gov.br/bvs/publicacoes/guia_implementar_avaliacoes_servicos_ hematologia.pdf >. Acesso em: 13 maio 2016.

CONSELHO NACIONAL DE SECRETÁRIOS DE SAÚDE (Brasil). Alternativas de gerência de unidades públicas de saúde. Brasília, DF, 1995. Disponível em: <http://www.conass.org.br/biblioteca/pdf/Alternativas-de-Gerencia-deUnidades-Publicas-de-Saude.pdf $>$. Acesso em: 13 maio 2016.

DONABEDIAN, A. Garantía y monitoría de la calidad de la atención médica: un texto introductorio. México: Instituto Nacional de Salud Pública, 1990.

DONABEDIAN, A. The quality of care: how can it be assessed? Journal of the American Medical Association, [Chicago], v. 260, n. 12, p. 1743-1748, 1988.

LEDESMA RODRÍGUEZ, L.; FRANCO CAMA, E. Implantación del sistema de gestión de la calidad ISO 9001:2000 em centros y servicios de transfusión. Madrid: Asociación Española de Hematologia y Hemoterapia: Sociedad Española de Transfusión Sanguínea, 2007.

MAGRETTA, J.; STONE, N. O que é gerenciar e administrar. Tradução de Hugo de Souza Melo. Rio de Janeiro: Campus, 2002.

MALIK, A. M.; SCHIESARI, L. M. C. Qualidade na gestão local de serviços e ações de saúde. São Paulo: Instituto para o Desenvolvimento da Saúde, 1998. (Série Saúde \& Cidadania, v. 3).

MINTZBERG, H. Managing: desvendando o dia a dia da gestão. Tradução de Francisco Araújo da Costa. Revisão técnica de Roberto Fachin. Porto Alegre: Bookman, 2010.

SOBREIRA, C. A. M. O Programa Nacional de Qualificação da Hemorrede $P N Q H$ : estudo de avaliabilidade no âmbito do Hemocentro Coordenador do Ceará. 2015. 100 f. Dissertação (Mestrado em Saúde Coletiva) - Instituto de Saúde Coletiva, Universidade Federal da Bahia, Salvador, 2015. Disponível em: <https://repositorio.ufba.br/ri/bitstream/ri/18320/1/DISS\%20MP.\%20 Christianne\%20Andrezza\%20Sobreira.\%202015.pdf>. Acesso em: 14 abr. 2016. 
TANAKA, O. Y.; MELO, C. M. M. Avaliação de serviços e programas de saúde para a tomada de decisão. In: ROCHA, A. M.; CESAR, C. L. G. (Ed.). Saúde pública: bases conceituais. São Paulo: Atheneu, 2008. p. 119-131.

VIEIRA-DA-SILVA, L. M. Avaliação de políticas e programas de saúde. Rio de Janeiro: Ed. Fiocruz, 2014. 